International Journal of Electrical and Power Engineering 4 (1): 19-26, 2010

ISSN: 1990-7958

(C) Medwell Journals, 2010

\title{
Load Effect on Switched Reluctance Starter/Generator System in Aircraft
}

\author{
Shoujun Song and Weiguo Liu \\ School of Automation, Northwestern Polytechnical University, P.O. Box 352, \\ 127 Youyi Xilu, Xi’an, 710072, Shaanxi, P.R. China
}

\begin{abstract}
Switched Reluctance Machine (SRM) is considered as a prime candidate for Combined Starter/Generator (CS/G) in More/All Electric Aircraft (M/A EA). In this study, the effect of the load on the power quality of the Switched Reluctance Starter/Generator (SR S/G) system is studied. The loads are mainly divided into three groups, namely conventional, special and constant power loads. Many simulation results, such as curves of output voltage and phase current under loading and unloading conditions are given. Furthermore, the effect of the Constant Power Loads (CPLs) on the system stability is analyzed briefly.
\end{abstract}

Key words: More/All Electric Aircraft (M/A EA), Combined Starter/Generator (CS/G), Switched Reluctance Machine (SRM), load effect analysis, power quality, system stability

\section{INTRODUCTION}

Many studies have indicated that More/All Electric Aircraft (M/A EA) technology is the future development trend of the aviation industry (Quigley, 1993; Cronin, 1990 ) and Combined Starter/Generator $(\mathrm{CS} / \mathrm{G})$ is a key subsystem of M/A EA (Ferreira and Richter, 1993; Weimer, 2003). Among kinds of machines that can be used as a CS/G in M/AEA, the Switched Reluctance Machine (SRM) is considered as a prime candidate to meet the requirements and constraints well (Schofield and Long, 2005; Ferreira et al., 1995a, b; Ferreira and Richter, 1993).

In the M/A EA, hydraulic and pneumatic systems are canceled. The majority/all of the aircraft's secondary power requirements is supplied in an electrical form (Jones, 1999). This makes the capacity and structure of the power supply system bigger and more complex. Furthermore, the type of the loads increases largely which will dramatically affect the power quality, system stability and electromagnetic compatibility of the airborne power supply system (Rosero et al., 2007; Weimer, 1993). So, it's necessary and very important to study the effects of the loads on SR S/G system in M/A EA.

Skvarenina et al. (1996) built a detailed model of the power supply system in more electric aircraft. On the basis of this model, the performances of the system were studied under different loading conditions include passive loads, Constant Power Loads (CPLs), Brushless DC Motors (BLDCMs) and so on. The experimental results were given as well as modified the system model built by Skvarenina et al. (1997) based on Graphics Modeler (GM) in Advanced Continuous Simulation Language (ACSL). The visualization and flexibility of the model were improved. Abouzeid (1998) studied the effects of the resistive and inductive loads on the phase current based on the transient phase inductance. The performances of the system were improved by adjusting the ratio between resistance and inductance in the load.

El-Nemr et al. (2003) developed a specialized tool box for SRM based on Object Oriented Programming (OOP) technology. The performances of the system were studied under the variations of the exciting voltage, speed of the prime motor, turn-on and turn-off angles. Gao et al. (2003) built a model of the high-voltage DC power supply system in the aircraft based on Matlab/PSB. The performances of the system under loading condition were studied by simulation. Han et al. $(2006,2008)$ built a state-space model of the 270 VDC power supply system.

The small-signal stability of the system was studied by eigenvalue method. Finally, the results of the theoretical analysis were verified by time domain simulation. Ferreira et al. (1995a, b) studied the stability of the SR S/G system with CPLs and capacitive loads. Experimental results verified the accuracy of the model. Wang and Howe (2007) proposed a novel method to control the stability of the DC power supply system under CPLs based on power shaping algorithm. The large-signal stability of the system was guaranteed while the output voltage was adjusted effectively. Zhou et al. (2002) analyzed the characteristics of the power supply system

Corresponding Author: Shoujun Song, School of Automation, Northwestern Polytechnical University, P.O. Box 352, 127 Youyi Xilu, Xi'an, 710072, Shaanxi, P.R. China 
in more electric aircraft. A method to guarantee the stability of the power supply system with CPLs in aircraft was proposed. Finally, the conditions to guarantee the system stability were given. Xie and $\mathrm{Pu}$ (2008) built the model of the high-voltage DC power supply system in the aircraft by the simulation method based on differential equations.

The stability of the system under the interaction between DC/DC module and CPLs was analyzed and the conditions to guarantee the system stability were obtained.

In this study, the effects of the loads on the power quality of the SR S/G system are studied. Three groups of loads, namely conventional, special and constant power loads are considered.

\section{CONVENTIONAL LOADS}

According to the electrical characteristics, as we know, the loads can be basically divided into three types: resistive, inductive and capacitive loads. The conventional loads considered here are simple combinations of these types of load. In this study, pure resistance (Load I), resistance in series with inductance (Load II) and the load with large input capacitance (Load III) are studied.

Figure 1 and 2 show the output voltage and phase current of the SR S/G system with Load I.
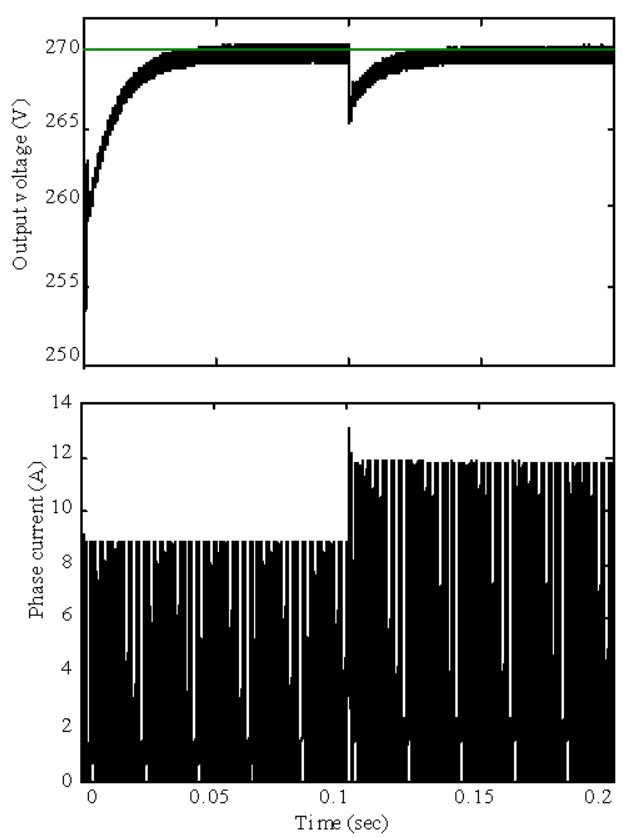

Fig. 1: Response of the system when load I increase (a) Output voltage (b) Phase current
In Fig. 1, the system is started with Load I $81 \Omega$. The load is changed to $40.5 \Omega$ at $0.1 \mathrm{sec}$. In Fig. 2 , the system is started with $40.5 \Omega$. The load is changed to $81 \Omega$ at $0.1 \mathrm{sec}$.

Figure 1 shows that when Load I increases, there is a sudden drop in the output voltage and the phase current increases accordingly.

After a short adjusting time, the output voltage returns to its steady-state setting value, namely $270 \mathrm{~V}$. When Load I decreases, the response of the system is reverse.

Figure 3 and 4 show the output voltage of the SR S/G system with the loading of Load I and Load II, respectively.

In Fig. 3, the system is started without load. Load $I 81 \Omega$ is added to the system at 0.03 sec. In Fig. 4, the system is started without load. Load II $81 \Omega$ in series with $1 \mathrm{~h}$ is added to the system at $0.03 \mathrm{sec}$.

Figure 4 shows that the existence of inductive load (Load II) can significantly decrease the falling speed and amplitude of the output voltage after loading.

However, the adjusting time will increase. The reason is that the current of the inductive load can't change suddenly. Consequently, the current of the load will

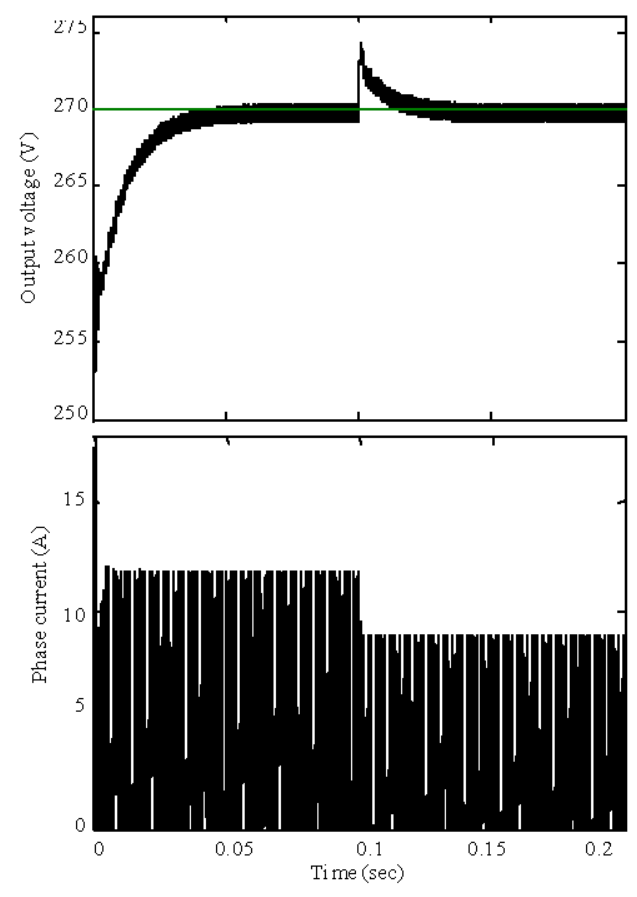

Fig. 2: Response of the system when load I decreases (a) Output voltage (b) Phase current 


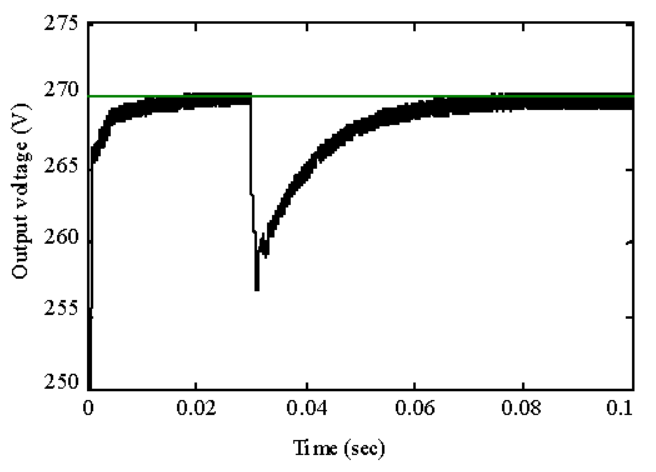

Fig. 3: Output voltage of the system with loading of load I

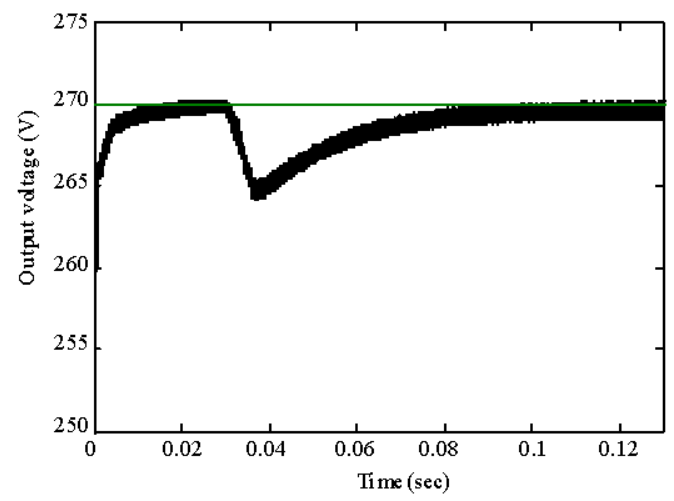

Fig. 4: Output voltage of the system with loading of load II

increase slowly. It can be considered as gradual loading. Figure 5 shows the load current with Load I and Load II.

Figure 6 shows the output voltage of the system when Load II is changed from light to heavy. The system is started with $81 \Omega$ and $1 \mathrm{~h}$. The load is changed to $40.5 \Omega$ and $1 \mathrm{~h}$ at $0.1 \mathrm{sec}$. It can be seen that when the load is changed from light to heavy, the output voltage will not decrease suddenly. Instead, it will increase firstly then decrease and return to its steady-state value finally. The reason for this is that when the load is changed, the current of the new load will increase gradually (Fig. 5b). Consequently, during a short period after the change, the load current will be smaller than that before the change. The rising speed and amplitude of the output voltage depend on the ratio between resistance and inductance in Load II.

In the aircraft, many electrical loads have input capacitances to smooth the current and decouple different systems. Figure 7 shows the output voltage of the system with the loading of Load III. The system is started without
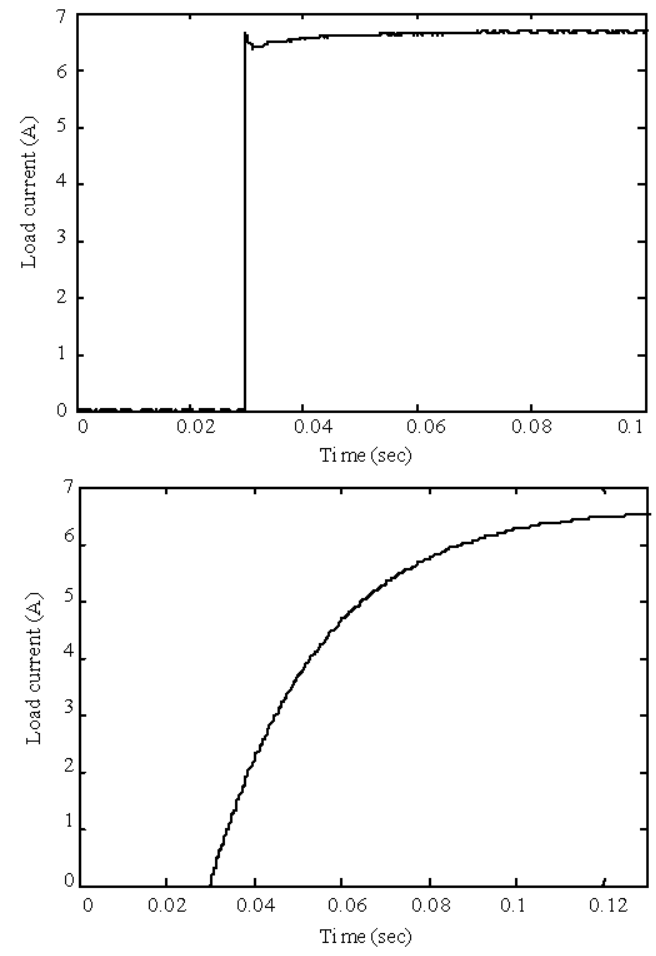

Fig. 5: Current of load I and load II (a) Load I (b) Load II

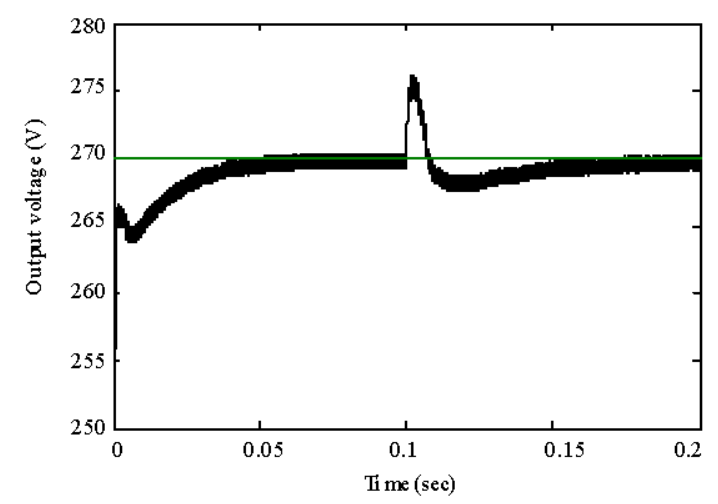

Fig. 6: Output voltage when load II is changed from light to heavy

load and Load III is added at $0.03 \mathrm{sec}$. Here, the structure of Load III is an $81 \Omega$ resistance connected with a $1 \mathrm{~h}$ inductance in series and then connected with a $1 \mathrm{mF}$ capacitance in parallel.

From Fig. 7, it can be seen that because the voltage of the capacitance can't change suddenly after loading, the output voltage will fall to the exciting voltage. The steadystate ripple of the output voltage will significantly decrease because of the filtering action of the capacitance. 


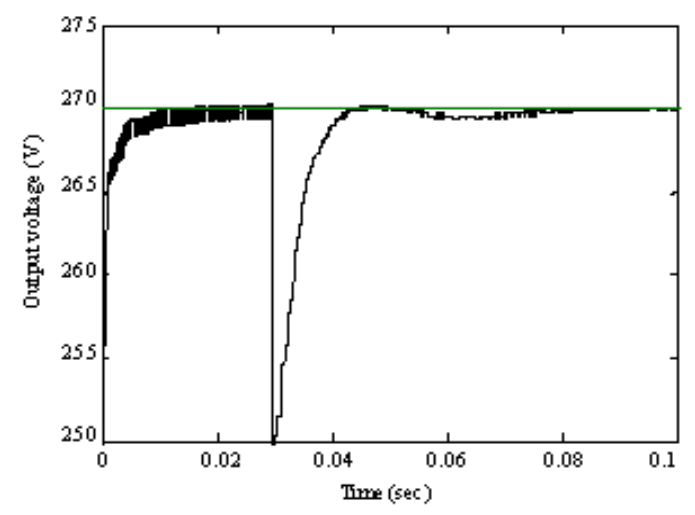

Fig. 7: Output voltage of the system with the loading of load III

\section{SPECIAL LOADS}

In M/A EA, the majority/all of the arborne units is supplied in an electrical form. This makes the type and amount of the loads increase largely. A single form of power can't meet the requirements of different types of loads simultaneously. Furthermore to optimize the performances of the power system, distributed highvoltage DC power supply system is adopted. All these make the amount of the DC/DC converters and DC/AC inverters increases largely. So, it's necessary to study the performances of the power system with these special loads.

Figure 8 shows the simulation results of the system with the loading and unloading of a closed-loop voltage control DC/DC converter (Load IV). The system is started with an $81 \Omega$ load and Load IV is added at $0.05 \mathrm{sec}$, then the fault of the SRM named LP (lack of phase) occurs at $0.1 \mathrm{sec}$, Load IV is removed at $0.15 \mathrm{sec}$ finally. The bus voltage, output voltage of Load IV and the phase current of the SRM are given. From the Fig. 8, it can be seen that after loading, the bus voltage decreases suddenly.

After a short adjusting time, it returns to the steady-state value and its ripple increases significantly. At the same time, the output voltage of the DC/DC converter achieves its setting value quickly. When the fault occurs, the ripple of the bus voltage further increases but the output voltage of the DC/DC converter is basically unaffected. After unloading, the output voltage of the $\mathrm{DC} / \mathrm{DC}$ converter gradually falls to zero. Because of the LP fault of the SRM, the steady-state ripple of the bus voltage is bigger than that before loading. These simulation results also verify that the SRM has strong fault-tolerant ability.

An outstanding feature of M/A EA is the wide application of electric actuators. Many motors are used to
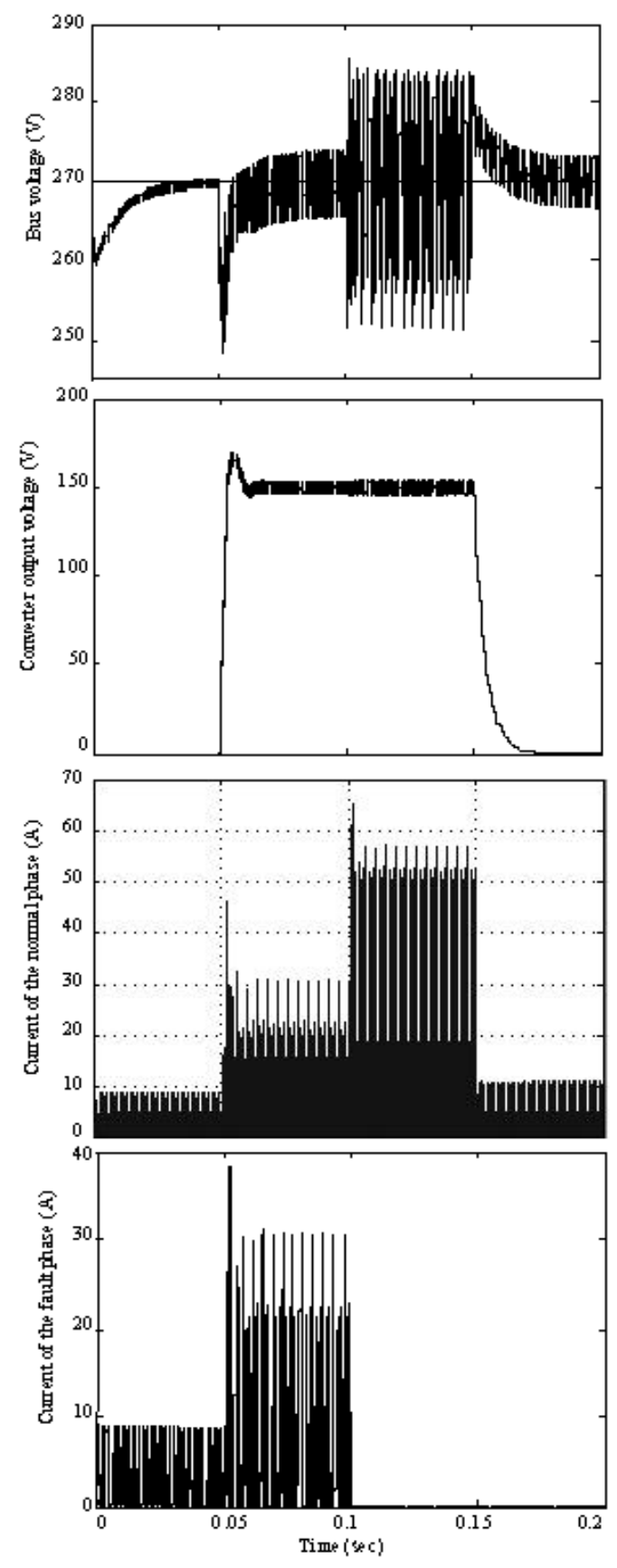

Fig. 8: Performances of the system with the loading and unloading of load IV (a) Bus voltage (b) Output voltage of the DC/DC converter (c) Current of the normal phase (d) Current of the fault phase

drive different types of actuators, pumps and so on. So it's necessary to study the performances of the system when the motor is considered as load.

Figure 9 shows the simulation results of the system with the loading and unloading of a closed-loop speed control DC motor (Load V). 
Int. J. Elec. Power Eng., 4 (1): 19-26, 2010
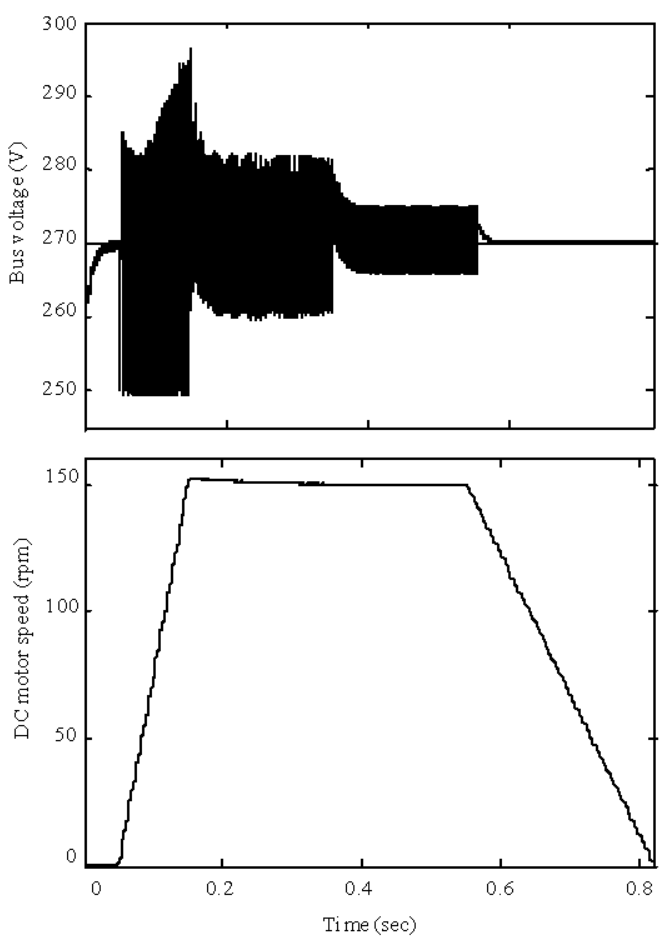

Fig. 9: Performances of the system with the loading and unloading of load V (a) Bus voltage (b) Speed of the DC motor

The system is started without load and Load $\mathrm{V}$ is added at $0.05 \mathrm{sec}$, then the speed of the prime motor changes from $7500-15000 \mathrm{rpm}$ at $0.35 \mathrm{sec}$, Load V is removed at $0.55 \mathrm{sec}$ finally. The bus voltage and the speed of the DC motor are given. From Fig. 9, it can be seen that after loading, the ripple of the bus voltage increases significantly. At the same time, the speed of the DC motor increases quickly.

When the speed of the motor reaches the setting value, the ripple of the bus voltage decreases. As the speed of the prime motor increases, the ripple of the bus voltage further decreases but the speed of the DC motor is basically unaffected. After unloading, the speed of the DC motor gradually falls to zero under the influence of inertia. Because the speed of the prime motor is still high, the ripple of the bus voltage is smaller than that before loading.

\section{CONSTANT POWER LOADS}

There are many Constant Power Loads (CPLs) in M/A EA. Their characteristic of positive feedback may cause the instability of the system. The definition and characteristics of the CPLs can be found in numerous literatures.

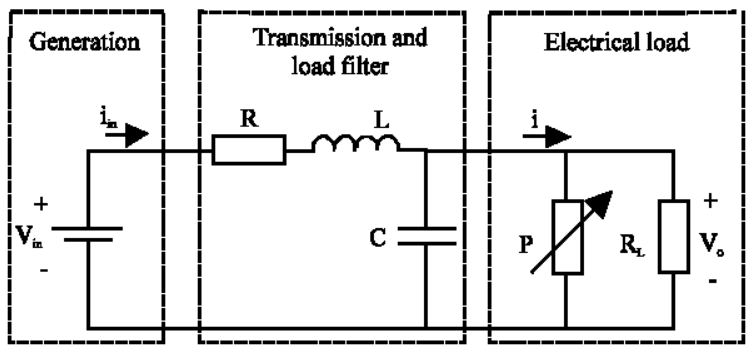

Fig. 10: The equivalent circuit of the distributed DC power supply system in M/A EA

In this study, the small-signal stability of the distributed DC power system in M/A EA with CPLs is studied briefly. The necessary and sufficient condition to guarantee the stability of the system is obtained and verified by simulation.

To study the stability of the power supply system, its structure should be analyzed firstly. In aircraft, the power supply system mainly consists of generation, transmission and load subsystems.

Figure 10 shows an equivalent circuit diagram of the distributed DC power supply system in M/A EA. To reduce the complexity of the analysis, each subsystem shown in Fig. 10 is simplified. The generation subsystem is expressed by a voltage source that has infinite hard characteristics.

The transmission lines and the filter of the load are indicated by $R, L$ and $C . P_{C P L}$ and $R_{L}$ represent the constant power and constant voltage loads, respectively.

According to some related circuital theorems, the voltage and current equations of the circuit shown in Fig. 10 can be easily written as:

$$
\left\{\begin{array}{l}
\mathrm{v}_{\text {in }}=\mathrm{Ri}_{\text {in }}+\mathrm{L} \frac{\mathrm{di}_{\text {in }}}{\mathrm{dt}}+\mathrm{v}_{0} \\
\mathrm{i}_{\text {in }}=\mathrm{C} \frac{\mathrm{dv}_{0}}{\mathrm{dt}}+\frac{\mathrm{P}}{\mathrm{v}_{0}}+\frac{\mathrm{v}_{0}}{\mathrm{R}_{\mathrm{L}}}
\end{array}\right.
$$

where, $\mathrm{P}$ is the power of the CPL.

Equation 2 shows the small-signal transfer function of the system. It can be obtained by the linearization of Eq. 1 around the rated operating point:

$$
\begin{aligned}
& \mathrm{H}(\mathrm{s})=\frac{\widetilde{\mathrm{V}}_{0}(\mathrm{~s})}{\widetilde{\mathrm{V}}_{\text {in }}(\mathrm{s})}= \\
& \frac{1 / \mathrm{CL}}{\mathrm{s}^{2}+\left(\frac{\mathrm{R}}{\mathrm{L}}+\left(\frac{1}{\mathrm{R}_{\mathrm{L}}}-\frac{\mathrm{P}}{\mathrm{V}_{0}^{2}}\right) \frac{1}{\mathrm{C}}\right) \mathrm{s}+\left(1+\frac{\mathrm{R}}{\mathrm{R}_{\mathrm{L}}}-\frac{\mathrm{RP}}{\mathrm{V}_{0}^{2}}\right) / \mathrm{CL}}
\end{aligned}
$$

where, $V_{0}$ is the rated output voltage of the system. 
According to some control theories to keep the system stable, all the poles of its transfer function should have negative real parts. So, based on Eq. 2, the necessary and sufficient condition to guarantee the small-signal stability of the system shown in Fig. 10 can be obtained as:

$$
\mathrm{P}<\frac{\mathrm{V}_{0}^{2}}{\mathrm{R}_{\mathrm{L}}}+\frac{R \mathrm{C}}{\mathrm{L}} \mathrm{V}_{0}^{2} \text { and } \frac{\mathrm{V}_{0}^{2}}{\mathrm{P}}>\frac{\mathrm{RR}_{\mathrm{L}}}{\mathrm{R}+\mathrm{R}_{\mathrm{L}}}
$$

From Eq. 3, it can be seen that the stability of the system is determined by many factors and it can be improved by increasing the rated output voltage $V_{0}$ and filter capacitor $C$ and decreasing the load resistor $R_{L}$ and transmission line inductor $\mathrm{L}$. However in practice, $\mathrm{V}_{0}, \mathrm{R}_{\mathrm{L}}$ and $\mathrm{L}$ are always fixed.

So, $\mathrm{C}$ is commonly used to improve the system stability (Glover and Sudhoff, 1998; Sudhoff et al., 1998; Belkhayat et al., 1995). By the way, although the resistance of the transmission line $\mathrm{R}$ can impact both inequations, its value is always fixed and limited by system loss. So, $\mathrm{R}$ is also not considered in this study.

To verify the correctness of above theoretical derivation, a simulation example is given. In Fig. 11, the system operates with pure resistive load in the beginning and the CPL is added at $1 \mathrm{sec}$.

The values of parameters are: $\mathrm{R}=0.01 \Omega, \mathrm{L}=10 \mathrm{mH}$, $\mathrm{C}=10 \mathrm{mF}, \mathrm{p}=30 \mathrm{~W}, \mathrm{R}_{\mathrm{L}}=10 \Omega$ and $\mathrm{V}_{\mathrm{o}} \approx \mathrm{V}_{\text {in }}=20 \mathrm{~V}$. Substituting there values into Eq. 3, it can be found that both inequations are satisfied and the system is stable.

From Fig. 11, it can be seen that the oscillation of the output voltage after loading is convergent. So, the system is stable. Figure 12 shows the output voltage of the system when CPL increases to $50 \mathrm{~W}$. Recalculating Eq. 3, it can be found that the first inequation is not satisfied.

From the figure, it can be seen that the oscillation of the output voltage after loading is divergent. So, the system is unstable.

To make the system stable again, the filter capacitance $\mathrm{C}$ need to be adjusted. Figure 13 shows the output voltage of the system when $\mathrm{C}$ increases to $0.1 \mathrm{~F}$.

Recalculating Eq. 3, it can be found that both inequations are satisfied again. From the figure, it can be seen that the oscillation of the output voltage after loading is convergent. So, the system is stable again

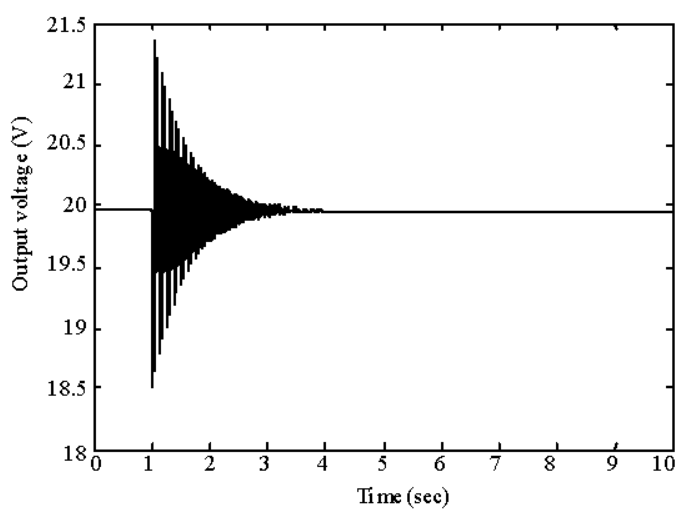

Fig. 11: Output voltage when the system is stable

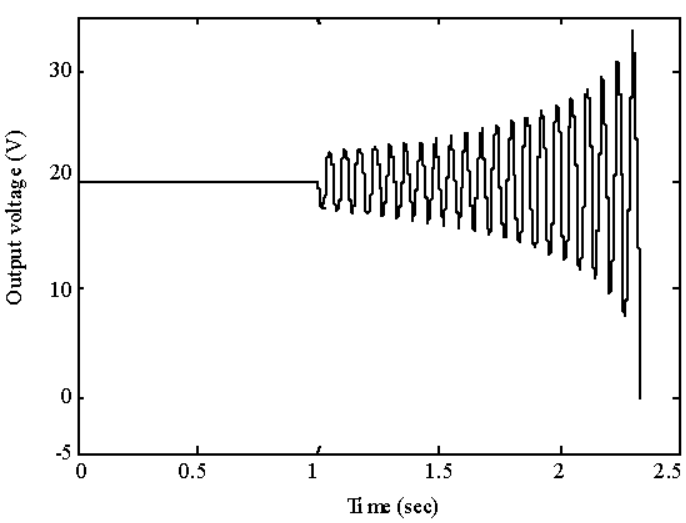

Fig. 12: Output voltage when the system is unstable

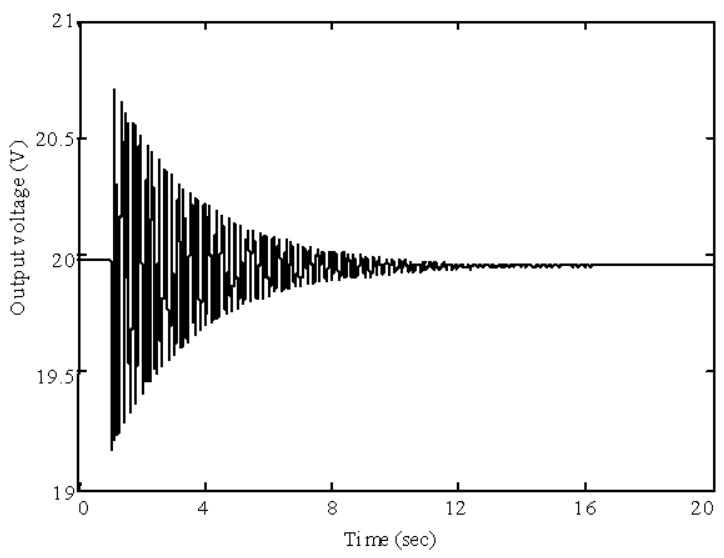

Fig. 13: Output voltage when the filter capacitance $C$ increases

\section{CONCLUSION}

In this study, the effects of the loads on the power quality of the SR S/G system in M/A EA are studied. 
Three groups of loads such as conventional, special and CPLs are considered. The conventional loads include resistance, resistance in series with inductance and the load with large input capacitance. The special loads include closed-loop voltage control DC/DC converter and closed-loop speed control DC motor. Many simulation results, such as curves of output voltage and phase current under loading and unloading conditions are given and analyzed.

Finally, the small-signal stability of the distributed DC power system in M/A EA with CPLs is studied briefly. The necessary and sufficient condition to guarantee the stability of the system is obtained and verified by simulation.

\section{REFERENCES}

Abouzeid, M., 1998. Load effect on the output current generated from the switched reluctance generator. Proceedings of the 7th International Conference on Power Electronics and Variable Speed Drives, Sept. 21-23, London, pp: 560-567.

Belkhayat, M., R. Cooley and A. Witulski, 1995. Large signal stability criteria for distributed systems with constant power loads. Proceedings of the IEEE 26th Power Electronics Specialist Conference (PESC'95), Atlanta, GA., pp: 1333-1338.

Cronin, M.J.J., 1990. The all-electric aircraft. IEE Rev., 36: 309-311.

El-Nemr, M.K., M.A. Al-Khazendar, E.M. Rashad and M.A. Hassanin, 2003. Modeling and steady-state analysis of stand-alone switched reluctance generators. Power Eng. Soc. Gen. Meet., 3: 1894-1899.

Ferreira, C.A. and E. Richter, 1993. Detailed design of a $250-\mathrm{kW}$ switched reluctance starter/generator for an aircraft engine. SAE Papers, Document No. 931389. http://www.sae.org/technical/papers/931389.

Ferreira, C.A., S.R. Jones, W.S. Heglund and W.D. Jones, 1995a. Detailed design of a $30-\mathrm{kW}$ switched reluctance starter/generator system for a gas turbine engine application. IEEE Trans. Industry Applic., 31: $553-561$.

Ferreira, C.A., S.R. Jones and W.S. Heglund, 1995 b. Performance evaluation of a switched reluctance starter/generator system under constant power and capacitive type loads. Proceedings of the 10th Annual Applied Power Electronics Conference and Exposition (APECE'95), Dallas, TX., pp: 416-424.

Gao, Z., X. Zhang and X. Wu, 2003. Simulation of high voltage direct current aircraft electrical power generating system base on MATLAB. J. Syst. Simulation, 15: 564-567.
Glover, S.F. and S.D. Sudhoff, 1998. An experimentally validated nonlinear stabilizing control for power electronics based power systems. SAE Papers, Document No. 981255.

Han, L., J. Wang and D. Howe, 2006. Small-signal stability studies of a $270 \mathrm{~V}$ DC more-electric aircraft power system. Proceedings of the 3rd IET International Conference on Power Electronics, Machines and Drives (PEMD'06), The Contarf Castle, Dublin, Ireland, pp: 162-166.

Han, L., J. Wang and D. Howe, 2008. Stability assessment of distributed DC power systems for more-electric aircraft. Proceedings of the 4th IET Conference on Power Electronics, Machines and Drives (PEMD'08), New York, pp: 661-665.

Jones, R.I., 1999. The more electric aircraft: The past and the future? Proceedings of the IEE Colloquium on Electrical Machines and Systems for the More Electric Aircraft, November 1999, London, UK., pp: 1-4.

Quigley, R.E.J., 1993. More electric aircraft. Proceedings of the 8th Annual Applied Power Electronics Conference and Exposition (APECE'93), San Diego, CA., pp: 906-911.

Rosero, J.A., J.A. Ortega, E. Aldabas and L. Romeral, 2007. Moving towards a more electric aircraft. IEEE Aerospace Electr. Syst. Mag., 22: 3-9.

Schofield, N. and S.A. Long, 2005. Generator operation of a switched reluctance starter/generator at extended speeds. IEEE Trans. Vehicle Power, 58: 453-460.

Skvarenina, T.L., O. Wasynczuk, P.C. Krause, W.Z. Chen, R.J. Thibodeaux and J. Weimer, 1996. Simulation and analysis of a switched reluctance generator/ more electric aircraft power system. Proceedings of the 31st Energy Conversion Engineering Conference, August 1996, Washington, DC, USA., pp: 143-147.

Skvarenina, T.L., S. Pekarek, O. Wasynczuk, P.C. Krause, R.J. Thibodeaux and J. Weimer, 1997. Simulation of a switched reluctance, more electric aircraft power system using a graphical user interface. Proceedings of the 32nd Intersociety Energy Conversion Engineering Conference, July 27-Aug. 1, Honolulu, HI, USA., pp: 580-584.

Sudhoff, S.D., K.A. Corzine, S.F. Glover, H.J. Hegner and H.N.Jr. Robey, 1998. DC link stabilized field oriented control of electric propulsion systems. IEEE Trans. Energy Convers., 13: 27-33.

Wang, J. and D. Howe, 2007. A novel power shaping stabilizing control strategy for DC power system with constant power loads. Proceedings of the IEEE Vehicle Power and Propulsion Conference (VPPC'07), Arlington, TX., pp: 20-25. 
Weimer, J.A., 1993. Electrical power technology for the more electric aircraft. Proceedings of the 12th AIAA/ IEEE Digital Avionics Systems Conference, October 1993, London, pp: 445-450.

Weimer, J.A., 2003. The role of electric machines and drives in the more electric Aircraft. Electr. Mach. Drives, 1: 11-15.
Xie, S. and M. Pu, 2008. Stability analysis of aircraft high voltage DC power system. Comput. Simulation, 25: 74-79.

Zhou, S., R. Qi and H. Lin, 2002. The loads stability analysis for more electric aircraft power system. Aeronautical Comput. Technol., 32: 93-95. 